\title{
The Next Iteration of The Journal of the American Board of Family Practice
}

\author{
Marjorie A. Bowman, MD, MPA, and Anne Victoria Neale, PhD, MPH
}

The Fournal of the American Board of Family Practice has made the transition to a fully on-line journal. This widely accessible format promises to increase the visibility of the fournal to clinicians, residents, and researchers, plus it will promote greater awareness of the important work of the American Board of Family Practice.

Your new editors intend to take full advantage of the capabilities of the on-line format to improve usefulness during the coming years. Many thanks to Dr. John Geyman, outgoing editor (see Dr. Paul Young's tribute at the front of the May-June issue), for all of his work over the years promoting excellence in family medicine research and specifically for making the initial transition to the electronic format.

Times are a-changing. Perhaps (oops, I know "perhaps" is wrong) some of you are like me. I can appreciate the ways technology helps through items such as better computer diagnostic tools, 24-hour bank tellers, on-line airline reservations, and Amazon.com, but sometimes I also fear it, such as how/when/why to switch our office to a computerized medical record system and-most important for this editorial—fully computerized electronic journals.

\section{The fournal of the American Board of Family Practice needs your help to make this the best journal it can be:}

\section{From the readers:}

Read

Send comments

Consider becoming an author http://www.jabfp.org/cgi/ feedback

\section{From the authors:}

Submit papers that empower the quality of care by family physicians

http://www.jabfp.org/misc/ifora/ shtml

From the reviewers:

Carefully review content, importance and readability http://www.jabfp.org/misc/ifora/ shtml

VOLUNTEERS NEEDED
Let's face it, we are familiar with: journals-in-the-john, journals-on-therun, journals-stacked-on-the-shelf. Perhaps (and yes, "perhaps" is now the right word) you are regularly using PubMed, Medscape, Up-to-Date, or other on-line literature or knowledge databases. For you, it might be a slight leap to this new on-line-only format for the journal. If, however, you are among those who are still not entirely comfortable in the electronic age, we invite you to explore the fournal Web site. You can have it all: The manuscripts are easily accessed and read on the computer screen. You can also print out high-quality, readable copies of the latest family practice research to read at your leisure. Your office will be neater, too-no more worries about running out of shelf space for journal storage.

We are now fully electronic in final publication but not yet in all of the editorial processing. This transition presents many challenges, some of which are beyond us alone, but help is available through the marvelous assistance and support of the American Board of Family Practice, as well as from outside entities, namely, Cadmus Professional Communications and HighWire Press. We are moving toward totally on-line manuscript submission.

We will take advantage of our electronic format to make $7 A B F P$ more pleasing to the eye and reader-friendly. Some changes will occur immediately; some will take time to develop. The articles will be easily readable on the computer screen. We want to make rapid responses from readers easier for you to send, thus making for lively, stimulating discussion among your colleagues. Please join in.

From the Department of Family Practice and Community Medicine (MAB), University of Pennsylvania Health System, Philadelphia; and the Department of Family Medicine, Division of Practice-based Research (AVN), Wayne State University School of Medicine, Detroit. Address reprint requests to Marjorie A. Bowman, MD, Department of Family Practice and Community Medicine, 3400 Spruce St, 2 Gates, Philadelphia, PA 19104-4283. 
Through all this, we will be emphasizing the relevance to the clinical practice of family medicine.

Through our experiences in family medicine as clinicians, researchers, authors, and editors, we have learned a few key items that we will bring to JABFP:

- Family physicians have diverse, eclectic interests and needs. Thus, we will provide a broad range of types of articles and science from case reports, clinical reviews, hard-core science, and the epidemiologic and social sciences-as long as they are pertinent and helpful to the practice of family medicine.

- Family physicians like easy-to-read tables and figures, clarity of message, and take-home points. Thus, a considerable part of our editing effort will go toward making this happen.

- Contrary to common opinion, family physicians value their learning from research articles as much as from clinical reviews. (When we asked family physicians which articles in the Archives of Family Medicine changed their practice, they mentioned research articles more often than clinical reviews.) Thus, we will make sure research articles provide clinically appropriate information related to their subject matter.

- We want to expand the domain of the $7 A B F P$. We encourage submissions in such areas as sports medicine, rural medicine, and geriatrics, papers that you might have previously targeted to specialty journals. We plan to create a niche for articles on clinical and research ethics.

- We need help to make this journal the best it can be. Thus, we will ask for your input, your service as peer reviewers of articles, your submission of material for publication, and your readership.

Take-Home Points

JABFP will use the advantages of its electronic format.

JABFP will be clinically relevant.

JABFP will be interesting and easy to read.

JABFP will improve the ability of family physicians to provide the best quality care.

JABFP has complete editorial freedom.
One of our goals is to improve the quality of care in family practice. This is not to say we do not have good quality of care, but that new information can and does improve how we treat our patients. As such, we will publish research in family medicine. This is not just an illusory, fuzzy goal, but a drive. It has been a driver for careers, and a driver of the American Board of Family Practice's decision to establish and maintain the fournal. To help make this goal happen, we have complete editorial freedom.

\section{RESEARCH OF, BY, AND FOR FAMILY PHYSICIANS}

Now the "monkey" is on your back - to read, to reflect, to apply the information, and to provide feedback to the authors and editors. If you want to receive e-mail notification of tables of contents when each new issue is available, go to the home page at www.jabfp.org, click on the button called "E-mail Alerts," and follow the instructions to sign up. There will also be a link (Sign up for eTOCs) on the table of contents page for each issue that will also take you to the sign-up page.

It is time to double-click and proceed!

\section{Short Professional Profile, Marjorie A. Bowman, MD, MPA, Editor}

Selected past and current experience pertinent to editorship of $7 A B F P$.

\section{Editing}

Editor, Archives of Family Medicine (for 8 years); editor, Fournal of Women's Health; editor, Yearbook of Family Practice, editorial board, $7 A M A$, American Family Physician, and Medical Practice Management. Reviewer for multiple other journals

\section{Research}

I have been an NIH-funded researcher and have published more than 100 articles and three books (Women Physicians: Life and Career Management, $3^{\text {rd }}$ Edition, Ambulatory Care of the Adult, and Office Emergencies). 


\section{Teaching}

My primary teaching is of medical students while I see patients, supervising residents in the office and hospital, a health promotion-disease prevention seminar for the family practice clerkship, and a leadership development seminar series for our fellows.

\section{Patient Care}

I see my own patients 2 half-days per week in Penn Family Care, and I participate in rotation with our inpatient service.

\section{Other}

Department chair at two different medical schools, currently the University of Pennsylvania, past president of the American Board of Family Practice, past president of the Society of Teachers of Family Medicine, and member of the Institute of Medicine.

For a more complete CV see the following Web site: http://www.uphs.upenn.edu/fampract/research/ extras.html\#faculty

\section{Short Professional Profile, Anne Victoria Neale, PhD, MPH, Deputy Editor Editing}

Feature editor, Family Medicine (6 years); editorial training, Workshop for New Editors at the Third International Congress on Biomedical Peer Review; Core Curriculum Certificate in medical writing and editing from the American Medical Writers Association, peer reviewer for many biomedical journals.

\section{Research}

Current funding from the US DHHS Office of Research Integrity, the Agency for Health Research \& Quality, and the Blue Cross Blue Shield of Michigan Foundation; 50 peer-reviewed publications in biomedical journals, received a 2002 research proposal incentive award from the Soy Health Research Program.

\section{Teaching}

Undergraduate medical education-course director for Research Methods in Family Medicine elective; graduate medical education-frequent lecturer on the topics of Technical Writing: Preparing the Biomedical Manuscript for Publication, Writing Grant Proposals, and Survey Research Methods; faculty development-Core Research Competencies.

\section{Other Professional Experience}

Associate Professor of Family Medicine, Wayne State University School of Medicine, and faculty in the Division of Practice-based Research; NHLBI post-doctoral fellowship in behavioral medicine; member, Council of Science Editors; member, World Association of Medical Editors; member, STFM Research Committee; and member, UK Committee on Research Ethics (COPE). 